\title{
On the future contract quality option: a new look
}

\author{
Alejandro Balbás ${ }^{\mathrm{a}}$ and Susana Reichardt ${ }^{\mathrm{b}, *}$ \\ ${ }^{a}$ Department of Business Economics, University Carlos III of Madrid, \\ CL Madrid, 126. 28903 Getafe, Madrid, Spain \\ ${ }^{\mathrm{b}}$ Department of Quantitative Methods, Universidad Alfonso X el Sabio. \\ Avda. de la Universidad, 1. 28691 Villanueva de la Cañada, Madrid, Spain
}

This article provides a new method for replicating and pricing the quality options usually embedded in many future contracts. The replicating strategies may draw on both the future contract as well as its related calls and puts. They also yield the quality option theoretical price in perfect markets, as well as upper and lower bounds for its bid or ask prices if frictions are incorporated. With respect to previous literature, this new approach seems to reflect five contributions: First, the analysis does not depend on any dynamic assumption concerning the Term Structure of Interest Rates (TSIR) behaviour; second, it incorporates the information contained in calls and puts on the future contract; third, it allows us to use real market perfectly synchronized prices; fourth, transaction costs can be considered and, finally, this article shows that the quality option may be a useful security in the portfolio of many traders. These traders will make the future contract more effective as a hedging instrument. This article also presents an empirical test involving the German market.

\section{Introduction}

This article deals with the quality option usually embedded in future contracts. Future contracts may incorporate four kinds of embedded options: The quality option (the future seller chooses the security to deliver from amongst a set of deliverable assets), the quantity option (the future seller chooses the quantity of the underlying asset to deliver), the temporary option (the future seller chooses the date within a time interval) and the localization option (the seller chooses the place). Some future contracts simultaneously incorporate several options.

We will focus on the quality option of future contracts on bonds, although the developed methodology also applies for more complex securities. Bond futures have a notional underlying asset and, consequently, the market organizers have to provide a list of deliverable bonds. A new flotation before the future expiration may provoke the enlargement of the list, and the future seller will decide at the future maturity the bond that he/she prefers to deliver.

The future buyer has no choice with respect to the asset he/she will receive, and therefore he/she merits compensation. Hence, the price of the future contract decreases and the detected fall has been the key used by many authors to price the embedded quality option. This price will critically depend on the volatility of the deliverable securities. If, as usual,

*Corresponding author. E-mail: sreich@uax.es 
they are bonds, then their volatility will be small and so will be the quality option price. But small price does not imply negligible price. On the contrary, as stated in Chance and Hemler (1993), to ignore the quality option may lead to important errors when composing hedging strategies and may underestimate many risk premiums or several measures of market efficiency (see also Kamara, 1990; Ahn et al., 2002; Merrick et al., 2005).

There are several alternatives for pricing the quality option, following the analysis of Chance and Hemler (1993). So, Margrabe (1978), Boyle (1989) and Hemler (1990) developed a theory to price the option allowing its buyer to change two previously fixed securities. Another possibility consists in pricing the option as the profit obtained by the future seller due to the difference in prices between the bond he/ she finally delivers and the one he/she would deliver when the future is sold (Kane and Marcus, 1986; Barnhill, 1990; Hedge, 1990; Hemler, 1990; Stickland, 1992). The usual way prices the option at any date before the future maturity as the difference between the theoretical future price of the cheapest to deliver bond and the future price reflected by the market (Hedge, 1990; Hemler, 1990; Stickland, 1992; $\mathrm{Yu}$, 1997). We will also follow this approach though, as will be justified, we will not draw on the cheapest to deliver asset. The last method indicated by Chance and Hemler (1993) prices the option by using the cash flows of a roll-over strategy that buys a (theoretical) future contract on the cheapest to deliver bond and sells the future contract (Barnhill and Seale, 1988; Barnhill, 1990; Hedge, 1990; $\mathrm{Yu}, 1997)$.

Recent papers (Bick, 1997; Chen, 1997) draw on the third method mentioned above and classic dynamic models of the Term Structure of Interest Rates (TSIR) behaviour (Vasicek, 1977; Cox et al., 1985) to price quality options. More complex models of the TSIR dynamics (Hull and White, 1990; Heath et al., 1992) are used in Lin and Paxson (1993), Ritchken and Sankarasubramanian (1995), Yu (1997), Chen et al. (1999), Henrard (2006) and Vidal and Ferreira (2007).

This article attempts to price the quality option by drawing on the standard methods of Pricing Theory, but the imposed assumptions are as simple as possible. First, a precise definition of the quality option is yielded. Second, it is proved that the quality options may be replicated with the available securities by means of a static portfolio, i.e. the replicating portfolio does not have to be rebalanced till the future maturity. Third, a simple arbitrage-linked argument allows us to provide the quality option with the price of its replica.

Dealing with a static replica seems to reveal several advantages. Indeed, our results are robust with regard to any dynamic assumption concerning the TSIR behaviour. Moreover, the static replica permits us to introduce transaction costs in a simple manner, so that they can be considered to price the replicating portfolio and the quality option. Finally, the replicating portfolio is not unique, since the future contract is close to the difference between its calls and puts. Clearly, the future contract options are affected by the presence of the quality option, so they contain information that may be quite interesting when pricing the quality option. Using the future contract options makes the analysis and the empirical results much more robust because they have to overcome different tests based on different replicating strategies. These properties are important since, as illustrated in Table 1, previous literature shows a great variation in different authors' estimates of the quality option value. Therefore, a high degree of precision in the analysis must be respected in order to achieve correct values.

It is also worth mentioning a final difference with respect to previous literature. As is well known, there is more than one quality option per future contract. Authors usually price the cheapest one in order to point out that the quality option effect is not so high. ${ }^{1}$ However, we have priced the most expensive quality option. This may be justified because, as mentioned above, the quality option may be replicated in a static framework and, consequently, it is available to traders. The quality option (or its replica) might be interesting by itself, in the sense that many traders could incorporate it in their portfolios so as to improve the usual ratios between the excess return and the risk level. If a trader decides to deal with the quality option, he/she will probably focus on the most expensive one, since, as will be illustrated, this option will not be affected by manipulators (see Järvinen and Käppi (2004) and Merrick et al. (2005) for recent analyses concerning manipulations). As will be shown, a fairly interesting consequence seems to be that traders dealing with the (most expensive) quality option could provide hedgers with liquidity and could compensate those effects provoked by manipulators, if they arise.

The outline of this article is as follows. Section II presents the theoretical results and the methodology.

\footnotetext{
${ }^{1}$ Note that if the quality option value were really negligible, then it would be difficult to understand some speculative behaviours pointed out by several authors (e.g. Merrick et al., 2005).
} 


\begin{tabular}{|c|c|c|c|}
\hline References & Future contract & Period or maturity & $\begin{array}{l}\text { Methodology and average } \\
\text { option price (as a percentage } \\
\text { of the nominal value) }\end{array}$ \\
\hline Kane and Marcus (1986) & US Treasury Bond & $\begin{array}{l}\text { September 1981, March } \\
\text { 1982, September 1982, } \\
\text { March } 1983\end{array}$ & 2.365 (M4) \\
\hline Barnhill and Seale (1988) & US Treasury Bond & $\begin{array}{l}\text { December } 1977 \text { to } \\
\text { December } 1984\end{array}$ & $1.1918 ; 0.28112$ (M5) \\
\hline Barnhill (1990) & US Treasury Bond & $\begin{array}{c}\text { December } 1977 \text { to } \\
\text { December } 1984\end{array}$ & $\begin{array}{l}0.25 ; 0.168 ; 0.117 ; 0.085 \text { (M4) } \\
1.191 ; 0.632 ; 0.281 ; 0.135 \text { (M5) }\end{array}$ \\
\hline Hedge (1990) & US Treasury Bond & $\begin{array}{c}\text { December } 1977 \text { to } \\
\text { December } 1986\end{array}$ & $\begin{array}{l}0.464(\mathrm{M} 3) \\
0.329(\mathrm{M} 4) \\
0.209(\mathrm{M} 5)\end{array}$ \\
\hline Hemler (1990) & US Treasury Bond & 1977 to 1986 & $\begin{array}{l}0.713 \text { (M1 } 2 \text { assets) } \\
1.243 \text { (M1 } 3 \text { assets) } \\
0.126 \text { (M3) } \\
0.245 \text { (M4) }\end{array}$ \\
\hline Stickland (1992) & Long Gilt & $\begin{array}{l}\text { March } 1987 \text { to } \\
\text { December } 1988\end{array}$ & $\begin{array}{l}0.214(\mathrm{M} 3) \\
0.227(\mathrm{M} 4)\end{array}$ \\
\hline Lin and Paxson (1993) & German Government Bond & $\begin{array}{l}\text { March } 1989 \text { to } \\
\text { December } 1991\end{array}$ & 0.095 (M2) \\
\hline $\begin{array}{l}\text { Ritchken and } \\
\text { Sankarasubramanian } \\
(1995)\end{array}$ & US Treasury Bond & September 1990 & $2.5642(\mathrm{M} 2)$ \\
\hline Yu (1997) & Japan Government Bond & $\begin{array}{l}\text { December } 1989 \text { to } \\
\text { March } 1994\end{array}$ & $\begin{array}{l}0.121(\mathrm{M} 2) \\
0.161(\mathrm{M} 3) \\
0.083(\mathrm{M} 5)\end{array}$ \\
\hline Chen et al. (1999) & Japan Government Bond & June 1990 to March 1994 & $0.021(\mathrm{M} 2)$ \\
\hline
\end{tabular}

Notes: We have not included those studies providing the global price of several embedded options, for instance, Gay and Manaster (1991).

M1: Methodology based on Margrabe (1978).

M2: Methodology based on a dynamic model for the TSIR behaviour.

M3: The quality option value is the difference between a future contract on the cheapest bond to deliver and the product of that bond conversion factor and the future price.

M4: The quality option price is the difference between the future seller earnings if he/she delivers the cheapest bond at maturity instead of the cheapest bond at the future contract sale.

M5: The quality option value is given by the earnings of a roll-over strategy holding at any instant the cheapest bond.

The two quality option values in Barnhill and Seale (1988) correspond to the transaction costs 0 and 25 basic points, respectively. Similarly, there are four values in Barnhill (1990) associated with the transaction costs 0, 12.5, 25 and 37.5 basic points.

We price the option in both perfect and imperfect markets. We yield several closed formulas related to the securities we are using when replicating the quality option (the future contract or its calls and puts). Section III deals with an empirical test implemented with the German Bund traded in European Exchange (EUREX). Two periods are analysed. The first one focuses on the future contract with maturity in December 2002, and the quality option was priced between 2 September 2002 and 6 December 2002 (last trading date). The second analysis considers the future contract with maturity in December 2005, and the quality option was priced from November 2 to November 18. Our first test did not use the future calls and puts and 3 months before maturity, the quality option approximate average value equalled $2 \%$ of the future contract nominal value. The quality option price decreased with time. This effect may affect the derivatives of the future contract and, therefore, as mentioned above, to ignore the quality option presence may cause other pricing errors (Ronn and Bliss, 1994 and Cherubini and Exposito, 1995, amongst others, have proposed a pricing method for options on futures with the embedded options). With regard to the second tested period, we have used the future contract calls and puts. The average value of quality option price was $2.5 \% 1$ month before maturity and was decreasing slowly. For the first period, the quality option price was around $1 \% 1$ month before maturity. There are two factors that could explain the difference: First, deliverable bonds of the future contract with 
maturity in December 2002 are the same coupon, whereas deliverable bonds of the future contract with maturity in December 2005 are different. Second, and probably less important, after the second tested period, a new bond was added to the list of deliverable bonds. Since the empirical evidence seems to reflect that the quality option price decreases as time increases, Section IV of this article verifies just how effective the simple investment strategy is: 'to sell the quality option and to buy it again a few days before its maturity'. ${ }^{2}$ It will be pointed out that the strategy was quite suitable, at least within the tested period, and, as already mentioned, it may compensate manipulations and improve the hedging demand of the future contract, since it preserves contract hedging effectiveness.

Finally, Section V of this article presents the major conclusions, and tables and figures illustrate the results of the empirical test.

\section{Replicating and Pricing the Quality Option}

The quality option will be replicated and priced by drawing on the classical static approach of Financial Economics. First, we will not incorporate frictions. Thus, consider the current date $t_{0}=0$ and a future one denoted by $T$. There are $n$ risky securities $S_{1}, S_{2}, \ldots, S_{n}$, a riskless asset, whose interest rate between 0 and $T$ is represented by $r$, and a future contract $F$ with maturity at $T$ and whose underlying assets are $S_{1}, S_{2}, \ldots, S_{n}$. The quality option will be exercised by the future seller. The (numerical) initial price of $S_{j}$ is denoted by $p_{0, j}, j=1,2, \ldots, n$, and $f$ is the initial future price. The (random) final price of $S_{j}$ will be $p_{j}, j=1,2, \ldots, n$, and $f^{*}$ will denote the future price at maturity.

There is a conversion factor $\delta_{j}>0$ that affects $S_{j}$, $j=1,2, \ldots, n$, so the pay-off received by the future seller at maturity is given by $f-f^{*}+\delta_{i} f^{*}-p_{i}$; If he/she delivers $S_{i}$. Of course, to prevent the existence of arbitrage at $T$, the expression $0=\left(\delta_{i} f^{*}-p_{i}\right) \geq$ $\left(\delta_{j} f^{*}-p_{j}\right) \forall j$ must hold, and we get

$$
f^{*}=\frac{p_{i}}{\delta_{i}} \leq \frac{p_{j}}{\delta_{j}} \quad \forall j
$$

Therefore, the final pay-off of the future seller becomes $f-f^{*}$. Security $S_{i}$ is usually called the cheapest asset to deliver.

Next, let us construct a new strategy replicating the sale of the previous future contract. So, fix $i$ between $j=1,2, \ldots, n$, and consider the derivative contract $F_{i}$ allowing the seller to deliver $1 / \delta_{i}$ units of $S_{i}$ at $T$ for $f$ monetary units. Let $Q_{i}$ be the option permitting the buyer to receive $1 / \delta_{i}$ units of $S_{i}$ at $T$ if he/she delivers $1 / \delta_{j}$ units of the chosen security $S_{j}$, that belongs to the set $\left\{S_{1}, S_{2}, \ldots, S_{n}\right\}$.

Proposition 1: The sale of $F$ may be replicated by the sale of $F_{i}$ and the purchase of $Q_{i}, i=1,2, \ldots, n$.

Proof: The sale of $F_{i}$ will pay $f-p_{i} / \delta_{i}$ and the purchase of $Q_{i}$ will pay $p_{i} / \delta_{i}-\operatorname{Min}_{j} p_{j} / \delta_{j}$ at $T$. Bearing in mind (Equation 1), the combination of both strategies will pay $f-f^{*}$, pay-off associated with a short position in $F$.

Remark 2: According to the abovementioned statement, the sale of $F$ incorporates $n$ implied quality options $Q_{1}, Q_{2}, \ldots, Q_{n}$. Each option $Q_{j}$ is associated with security $S_{j}, j=1,2, \ldots, n$.

Proposition 3: The price of $Q_{j}$ is given by

$$
q_{j}=\frac{p_{0, j}}{\delta_{j}}-\frac{f}{(1+r)^{T}} \quad j=1,2, \ldots, n
$$

Proof: The Law of One Price (LOP) and Proposition 1 lead to $0=A_{j}+q_{j}$ where $A_{j}$ is the price of a short-sale of $F_{j}$. Thus, it is sufficient to show that $A_{j}=\left(f /(1+r)^{T}\right)-\left(p_{0, j} / \delta_{j}\right)$ which is obvious since the sale of $F_{j}$ is replicated by lending $f /(1+r)^{T}$ monetary units and selling $1 / \delta_{j}$ units of $S_{j}$.

Remark 4: Expression (Equation 2) clearly points out that all the implied quality options do not necessarily have the same price. We will consider the most expensive one in order to introduce the quality option price', i.e.

$$
q=\max _{j}\left(\frac{p_{0, j}}{\delta_{j}}-\frac{f}{(1+r)^{T}}\right)
$$

will be the value that we will estimate in our empirical test.

The literature has focused on the quality option associated with the bond (or, more generally, security) that the future seller would deliver if the decision

\footnotetext{
${ }^{2}$ Let us remark that we do not trade the quality option itself. We just trade the replicating portfolio of the quality option, which is composed of real securities available in the market. Consequently, the returns provided by this strategy do not depend at all on the model we use to price the quality option. On the contrary, these returns are computed by using real bid/ask prices quoted in the market. They would remain the same if we drew on alternative pricing models for the quality option.
} 
were made at the initial date $t_{0}$, and it may be easily proved that this option price is given by (Equation 3) if the maximum value is replaced by the minimum value. Thus, Definition 3 is an important difference with respect to previous works. However, we prefer to concentrate on the option with the highest value because this is also related to the future contract $F$, in the sense that it can also be replicated by using $F$ (Proposition 1), and the empirical analysis will reflect that its value is not negligible. Moreover, expression (Equation 2) shows that the only difference between the cheapest and the most expensive quality options is given by a position in the involved bonds (in proportions given by the conversion factors). Thus, both the replicating portfolios are almost identical with the only difference being the bond to be traded. In this sense, if we consider that the quality option is an interesting security by itself, then the price of both options should dynamically reflect quite parallel behaviours. However, the expensive option will not be affected by the lack of the underlying bond if manipulators appear (Järvinen and Käppi, 2004; Merrick et al., 2005).

Note that the list of deliverable assets is often open in practice, in the sense that before $T$, the market organizers can add new securities to the set $S_{1}, S_{2}, \ldots, S_{n}$. Furthermore, this is the case when dealing with the Bund Future Contract, the one we will empirically check. Nevertheless, if we assume that the list of deliverable assets may be enlarged in the same manner when analysing the position of the $Q_{i}$ option buyer, then Proposition 1 still holds, and the proof is absolutely similar and therefore omitted. Then we have:

Proposition 5: Proposition 1 still holds if the set of deliverable securities may be enlarged before $T$.

Let us now assume that there exists transaction costs given by the usual bid/ask spread. Suppose that $f_{a}, f_{b}\left(f_{a} \geq f_{b}\right)$ and $p_{0, j}^{a}, p_{0, j}^{b}\left(p_{0, j}^{a} \geq p_{0, j}^{b}\right), j=1,2, \ldots, n$, are the ask and bid prices at $t_{0}=0$. Let $r_{a}$ and $r_{b}$ $\left(r_{a} \geq r_{b}\right)$ be the borrowing and lending interest rate between $t_{0}$ and $T$. We will not consider frictions at the second date.

Proposition 6: The upper and lower bounds below must hold

$$
\frac{p_{0, j}^{b}}{\delta_{j}}-\frac{f_{a}}{\left(1+r_{b}\right)^{T}} \leq q_{j} \leq \frac{p_{0, j}^{a}}{\delta_{j}}-\frac{f_{b}}{\left(1+r_{a}\right)^{T}} \quad j=1,2, \ldots, n
$$

\footnotetext{
${ }^{3}$ See Lieu (1990) for further details on this kind of option.
}

Proof: First of all,

$$
q_{j}-\left(\frac{p_{0, j}^{b}}{\delta_{j}}-\frac{f_{a}}{\left(1+r_{b}\right)^{T}}\right) \geq 0 \quad j=1,2, \ldots, n
$$

that is, if one buys the quality option and sells its replica, there are no positive incomes. Besides,

$$
\frac{p_{0 j}^{a}}{\delta_{j}}-\frac{f_{b}}{\left(1+r_{a}\right)^{T}}-q_{j} \geq 0 \quad j=1,2, \ldots, n
$$

that is, if one buys the quality option replica and sells the option, one cannot expect any positive income.

Remark 7: First, note that Proposition 6 extends Proposition 3. Second, both expressions must be slightly modified if $S_{j}$ pays the dividend (or coupon) $d_{j}$ at $\tau_{j}\left(t_{0} \leq \tau_{j} \leq T\right)$. If so,

$$
\begin{aligned}
& \frac{p_{0, j}^{b}}{\delta_{j}}-\frac{f_{a}}{\left(1+r_{b}\right)^{T}}-\frac{d_{j}}{\delta_{j}\left(1+r_{\tau_{j}}^{b} \tau^{\tau_{j}}\right.} \leq q_{j} \\
& \quad \leq \frac{p_{0, j}^{a}}{\delta_{j}}-\frac{f_{b}}{\left(1+r_{a}\right)^{T}}-\frac{d_{j}}{\delta_{j}\left(1+r_{\tau_{j}}^{a}\right)^{\tau_{j}}}
\end{aligned}
$$

for $j=1,2, \ldots, n$, and the proof is absolutely similar and therefore omitted. Third, all the expressions hold if more deliverable assets may be added before $T$.

Next, we will expand the methodology allowing us to draw on the information contained in calls and puts on the future contract in order to price the quality option. Therefore, along with the securities mentioned above, we will consider the existence of American calls and puts with the same strike $X$ and maturity at $T^{\prime}\left(T^{\prime}<T\right)$. Since the empirical test will draw on the quality option implied in the German Bund, we will consider the properties of its future options. Hence, the calls and puts mentioned above are 'pure options', i.e. the premium will be paid at $T^{\prime}$ or when the option is exercised if there is early exercise. ${ }^{3}$

Proposition 8: Suppose that there are no frictions and denote by $c$ and $p$ the call and put price, respectively. Then,

$$
q_{j}=\frac{p_{0, j}}{\delta_{j}}+\frac{p-c-X}{(1+r)^{T}} \quad k=1,2, \ldots, n
$$

Proof: The put-call parity relationship for European or American 'pure options' (Lieu, 1990) leads to $p-c=X-f$. Thus, expression (Equation 6) trivially follows from (Equation 2). 
Remark 9: As in Remark 7, if $S_{j}$ pays the dividend (or coupon) $d_{j}$ at $\tau_{j}\left(t_{0} \leq \tau_{j} \leq T\right)$, then the quality option price satisfies

$$
q_{j}=\frac{p_{0, j}}{\delta_{j}}+\frac{p-c-X}{(1+r)^{T}}-\frac{d_{j}}{\delta_{j}\left(1+r_{\tau_{j}}\right)^{\tau_{j}}} \quad j=1,2, \ldots, n
$$

$r_{\tau_{j}}$ being the risk-free rate between $t_{0}$ and $\tau_{j}$. The expression also holds if the set of deliverable securities may grow before $T$.

Next, let us assume the existence of transaction costs. Let $c_{a}, c_{b}\left(c_{a} \geq c_{b}\right)$ and $p_{a}, p_{b}\left(p_{a} \geq p_{b}\right)$ be the ask and the bid prices of the call and the put option. Then, one has the following:

Proposition 10: The inequalities below must hold

$$
\frac{p_{0 j}^{b}}{\delta_{j}}+\frac{p_{b}-c_{a}-X}{\left(1+r_{a}\right)^{T}} \leq q_{j} \leq \frac{p_{0 j}^{a}}{\delta_{j}}+\frac{p_{a}-c_{b}-X}{\left(1+r_{b}\right)^{T}} j=1,2, \ldots, n
$$

Proof: According to Jouini and Kallal (1995), the absence of arbitrage in a market with frictions implies the existence of an (ideal) arbitrage-free frictionless market whose prices lie within the bid/ask spread. Thus, there exists $p_{0, j}, j=1,2, \ldots, n, c, p$, and a riskfree rate $r$ such that $p_{0 j}^{b} \leq p_{0 j} \leq p_{0 j}^{a}, j=1,2, \ldots, n$, $c_{b} \leq c \leq c_{a}, p_{b} \leq p \leq p_{a}, r_{b} \leq r \leq r_{a}$ and Equation 6 holds. Whence, Equation 8 becomes obvious.

Remark 11: Once again, the presence of dividends $d_{j}$ at $\tau_{j}\left(t_{0} \leq \tau_{j} \leq T\right)$ leads to

$$
\begin{gathered}
\frac{p_{0 j}^{b}}{\delta_{j}}+\frac{p_{b}-c_{a}-X}{\left(1+r_{a}\right)^{T}}-\frac{d_{j}}{\delta_{j}\left(1+r_{\tau_{j}}^{b}\right)^{\tau_{j}}} \leq q_{j} \\
\leq \frac{p_{0 j}^{a}}{\delta_{j}}+\frac{p_{a}-c_{b}-X}{\left(1+r_{b}\right)^{T}}-\frac{d_{j}}{\delta_{j}\left(1+r_{\tau_{j}}^{a}\right)^{\tau_{j}}}
\end{gathered}
$$

$j=1,2, \ldots, n$. Moreover, an additional flotation would not modify the formulas.

\section{Empirical Test: Data and Results}

Table 1 summarizes the prices of the quality options that were obtained in the previous literature. This table has been provided for two reasons: first, it allows us to compare different results and second, it may be seen that the German Bund is not the usual focus of empirical papers. However, the German Bund Future presents an interesting property since it only contains the quality options, and no more options are simultaneously embedded.

There is great variation in different authors' estimates of the quality option value. This may be justified by several reasons. First, high correlations amongst the assets in the deliverable set make the quality option price decrease (for instance, note that those quality options related to American markets usually reflect larger values, since the deliverable assets are more heterogeneous). Second, the volatility of the TSIR also makes the quality option value grow, so those analyses related to periods with high volatility levels will show this effect. Third, the future contracts involved present different characteristics (some of them contain more than one embedded option). Fourth, as mentioned in Section I, there are several methodologies that apply when pricing the quality option. These methodologies often imply a different formal definition of the quality option, which justifies different values. This is the reason why we decided to define with precision the quality option in Section II. Finally, some authors do not draw on synchronized high frequency market prices, which may provoke some estimation errors (many papers use the last price as the only one per day).

We used the German Bund Future Contract, available in EUREX, to test the quality option price. The underlying asset is a notional bond issued by the German government whose annual coupon equals $6 \%$. The contract nominal value is 100000 euros and prices represent a percentage of the nominal value with two decimal digits. There are four available maturities, March, June, September and December, although the shortest one reflects the greatest activity. The future contract can be traded until 1 day before its maturity at $12: 30 \mathrm{pm}$. The delivery must take place on the 10th day of the delivery month, and the deliverable assets are bonds issued by the German government with maturity between 8.5 and 11.5 years. The set of deliverable assets may increase, if a new flotation occurs and the new bonds satisfy some required conditions.

We have addressed two empirical tests. Both analyses draw on high frequency perfectly synchronized data in order to price the quality option with the highest possible precision. ${ }^{4}$ The first one does not use future options and focuses on the future contract with maturity in December 2002. The quality option price has been computed between September 2 and December 6 (last trading day). In order to use

\footnotetext{
${ }^{4}$ We follow the ideas and precision of the empirical study of Balbás et al. (2000), where the level of integration between the Spanish spot and derivative markets is verified by using a similar database.
} 
Table 2. Deliverable bonds

\begin{tabular}{|c|c|c|c|c|c|c|c|}
\hline \multicolumn{4}{|c|}{ Future maturity in December 2002 (first study) } & \multicolumn{4}{|c|}{ Future maturity in November 2005 (second study) } \\
\hline $\begin{array}{l}\text { Coupon } \\
(\%)\end{array}$ & $\begin{array}{l}\text { Coupon } \\
\text { payment }\end{array}$ & Maturity & $\begin{array}{l}\text { Conversion } \\
\text { factor }\end{array}$ & $\begin{array}{l}\text { Coupon } \\
(\%)\end{array}$ & $\begin{array}{l}\text { Coupon } \\
\text { payment }\end{array}$ & Maturity & $\begin{array}{l}\text { Conversion } \\
\text { factor }\end{array}$ \\
\hline 5 & July 4 & 4 July 2011 & 0.934161 & 4.25 & July 4 & 4 July 2014 & 0.885160 \\
\hline 5 & January 4 & 4 January 2012 & 0.931496 & 3.75 & January 4 & 4 January 2015 & 0.846069 \\
\hline 5 & July 4 & 4 July 2012 & 0.928434 & 3.25 & July 4 & 4 July 2015 & 0.803899 \\
\hline
\end{tabular}

Table 3. Quality option price

\begin{tabular}{|c|c|c|c|c|c|c|}
\hline & \multicolumn{2}{|c|}{ Price (frictionless) } & \multicolumn{2}{|c|}{ Lower bounds } & \multicolumn{2}{|c|}{ Upper bounds } \\
\hline & Average & $\mathrm{SD}$ & Average & $\mathrm{SD}$ & Average & $\mathrm{SD}$ \\
\hline 10 September 2002 & 2067.9334 & 13.9782 & 2018.4435 & 19.5208 & 2116.5909 & 19.8424 \\
\hline 17 September 2002 & 2044.1395 & 17.8446 & 1997.7596 & 17.7651 & 2087.7974 & 20.8282 \\
\hline 24 September 2002 & 1982.6329 & 20.4426 & 1934.7991 & 23.4806 & 2029.4700 & 22.4364 \\
\hline 1 October 2002 & 1811.3299 & 23.8257 & 1764.9097 & 30.3892 & 1860.6771 & 22.0386 \\
\hline 8 October 2002 & 1585.5814 & 10.3722 & 1541.2431 & 16.2681 & 1629.2118 & 15.9634 \\
\hline 15 October 2002 & 1356.7231 & 15.3214 & 1310.2976 & 16.1995 & 1399.0561 & 15.7278 \\
\hline 22 October 2002 & 1193.6023 & 8.8620 & 1150.5683 & 12.0879 & 1236.5845 & 11.2627 \\
\hline 29 October 2002 & 1070.6210 & 11.9366 & 1030.2980 & 18.3060 & 1113.6743 & 17.5307 \\
\hline 5 November 2002 & 919.9963 & 11.2303 & 879.8488 & 14.7958 & 960.9985 & 14.8429 \\
\hline 12 November 2002 & 904.6217 & 7.0179 & 860.0444 & 14.8944 & 939.7295 & 13.1983 \\
\hline 19 November 2002 & 802.0046 & 8.0243 & 767.4107 & 9.7719 & 843.3840 & 7.8334 \\
\hline 26 November 2002 & 663.4569 & 10.1989 & 625.5274 & 14.4004 & 700.4784 & 14.5163 \\
\hline 3 December 2002 & 602.2256 & 9.1027 & 564.0362 & 14.7344 & 640.0106 & 15.4790 \\
\hline
\end{tabular}

Note: Values in euros; first study.

perfectly synchronized data, we only priced the option at those minutes so as to include all of the involved prices. ${ }^{5}$ Minute by minute, we have priced the quality option by considering bid and ask prices of the set of deliverable bonds and the future contract. We have also distinguished between borrowing and lending rates.

The future contract presents three quality options, since there were three bonds involved. There was no new flotation before the future expiration (Table 2). The conversion factor is the bond price per unit of nominal value, at the future expiration and under a flat TSIR equal to the notional bond coupon $(6 \%$, if we deal with the German Bund).

First of all, we computed the price of the three quality options under the frictionless assumption. At every minute, we took average values of the bid and ask prices for all the involved securities, including the risk-free rate. Minute by minute, the highest price corresponded to the quality option associated with the bond with longest maturity. According to
(Equation 3), this is the quality option price that we measured. Table 3 provides daily average values of the quality option, which clearly decreases and shows a negative slope (13 weeks before maturity, the quality option value equals $2 \%$ of the future nominal value, whereas 1 week before expiration, it falls to $0.6 \%$ ).

In a second step, we incorporated transaction costs and estimated the upper and lower bounds of the quality option price. We always found that both the bounds were associated with the bond with longest maturity. Furthermore, the three spreads showed void intersection. Table 3 gives daily average values for the bounds. Figures 1-3 provide the dynamic evolution of both the quality option price in a frictionless world and the bounds in a world with frictions. It is easy to check the stability of the distance between the quality option price and its bounds. The difference between the upper bound and the price almost equal the difference between the price and the lower bound (they usually lie within the

${ }^{5} \mathrm{We}$ had the bond prices and the future price minute by minute, but we did not get the interest rates. Thus, several minutes have been removed and our analysis involved 1250 minutes. 


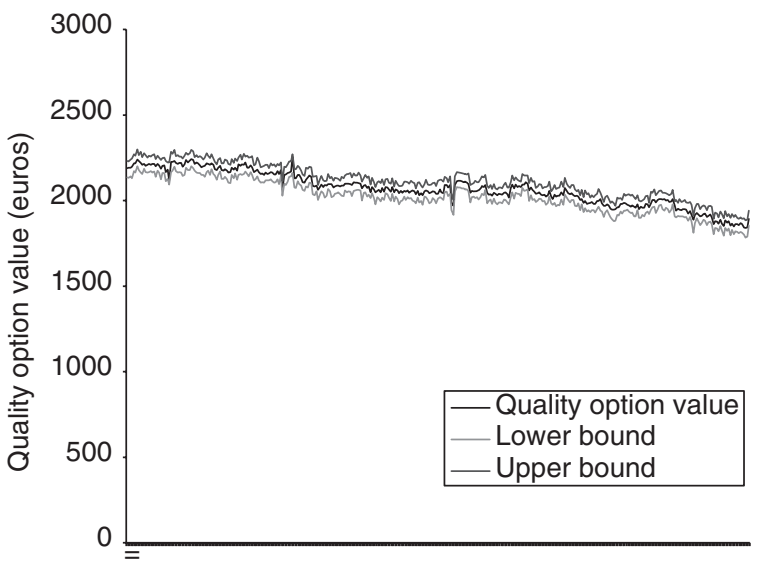

Fig. 1. Quality option price

Note: Value in euros; first study; September 2002; first bid/ask within the minute.

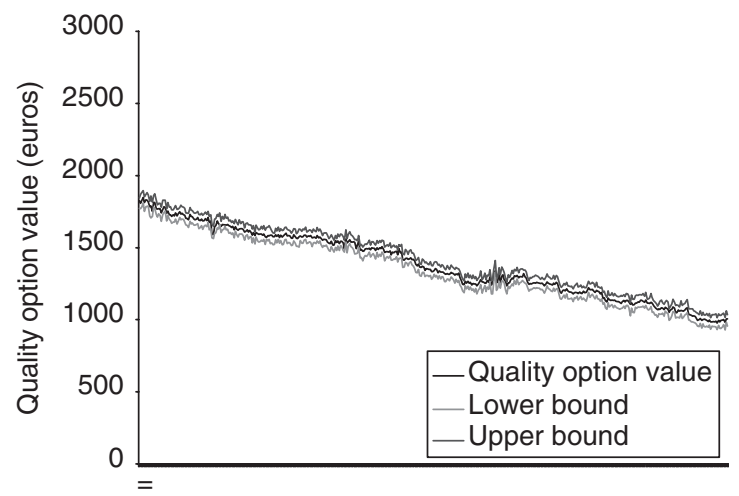

Fig. 2. Quality option price

Note: Value in euros; first study; October 2002; first bid/ask within the minute.

spread of 35-55 euros). Our second analysis involves pure options on the future contract. The options can be traded at any date before their expiration. Our study deals with pure options whose underlying future matured in December 2005. Table 2 summarizes the deliverable bonds properties. The quality option price was obtained from 2 November 2005 to 18 November 2005. We took the strikes 119, 119.5, 120 and 120.5, since our database contained its premiums perfectly synchronized with the remaining variables. ${ }^{6}$

First, we computed the three quality option values in a frictionless world. The result is similar to that obtained when dealing with the future

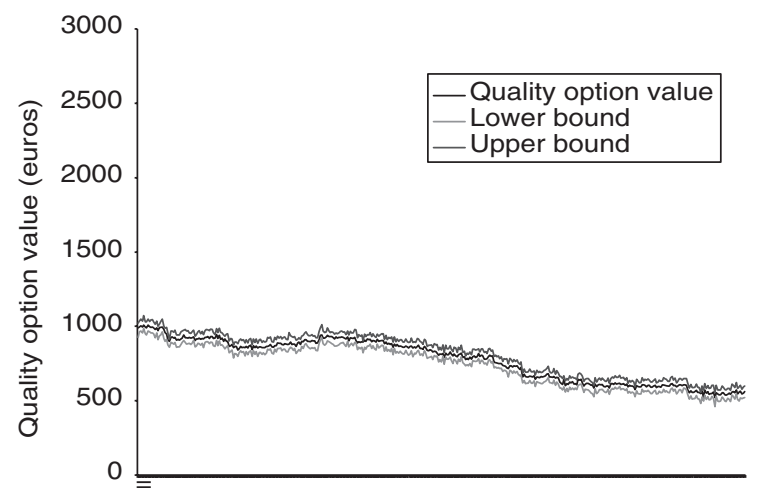

Fig. 3. Quality option price Note: Value in euros; November 2002 to 6 December 2002; first study; first bid/ask in the minute.

contracts rather than their pure options, in the sense that the quality option value rises if the associated bond maturity does as well. We follow Equation 3 to define the (global) quality option value, and Tables 4-7 give average values of the quality option price, which is usually close to $2.5 \%$ of the nominal.

Then, we considered transaction costs and computed bounds of the quality option price. Once again, the bounds are given by the bond with the highest maturity, and the deliverable bonds provided spreads with empty intersection. Tables 4-7 give daily average values for the bounds. Figures 4-7 show the dynamic evolution (fall) of the quality option price and its bounds. The distance between the price and its bounds is stable and lies within the spread of 50-60 euros. Overall, the results are coherent and robust, in the sense that the existence of four different strikes does not generate contradictions. On the contrary, every strike yields additional information with respect to the remaining ones.

\section{Investment Strategies Involving the Quality Option}

The existence of the quality option, or the existence of more than one deliverable asset, is justified by two important reasons: It makes the liquidity level increase and makes it rather difficult to manipulate the market prices. However, as pointed out by Järvinen and Käppi (2004) or Merrick et al. (2005), amongst others, manipulation might be still possible

${ }^{6}$ We used strike 119 to price the quality option in 86 minutes, 119.5 was used in 182 minutes, 120 in 161 minutes and 120.5 in 92 minutes. The remaining strikes were not used due to the scarce number of minutes that we could have studied. 


\begin{tabular}{|c|c|c|c|c|c|c|}
\hline & \multicolumn{2}{|c|}{ Price (frictionless) } & \multicolumn{2}{|c|}{ Lower bounds } & \multicolumn{2}{|c|}{ Upper bounds } \\
\hline & Average & SD & Average & SD & Average & SD \\
\hline 1 November 2005 & 2685.2436 & 7.6464 & 2613.8875 & 8.1496 & 2756.6018 & 8.6659 \\
\hline 4 November 2005 & 2609.4458 & 0.0000 & 2553.9559 & 0.0000 & 2664.9363 & 0.0000 \\
\hline 7 November 2005 & 2595.3872 & 0.0000 & 2530.3113 & 0.0000 & 2660.4642 & 0.0000 \\
\hline 8 November 2005 & 2596.4735 & 1.7027 & 2533.2961 & 23.6497 & 2659.6518 & 0.2448 \\
\hline 9 November 2005 & 2563.2335 & 6.2583 & 2496.0572 & 4.4001 & 2630.4106 & 16.0480 \\
\hline 10 November 2005 & 2543.5503 & 6.7821 & 2488.8216 & 8.7481 & 2598.2795 & 5.6524 \\
\hline 11 November 2005 & 2537.2235 & 3.7607 & 2478.5991 & 5.1632 & 2595.8485 & 3.0913 \\
\hline 14 November 2005 & 2501.9301 & 1.7393 & 2446.1114 & 22.4921 & 2557.7493 & 15.2036 \\
\hline 15 November 2005 & 2466.9911 & 1.7389 & 2410.5681 & 17.0990 & 2523.4147 & 17.1664 \\
\hline 16 November 2005 & 2506.2085 & 3.5046 & 2444.9190 & 26.5708 & 2567.4986 & 37.3877 \\
\hline 18 November 2005 & 2432.1862 & 14.3861 & 2369.3658 & 15.7281 & 2495.0072 & 18.1703 \\
\hline
\end{tabular}

Note: Values in euros; second study; strike $=119$.

Table 5. Quality option price

\begin{tabular}{|c|c|c|c|c|c|c|}
\hline & \multicolumn{2}{|c|}{ Price (frictionless) } & \multicolumn{2}{|c|}{ Lower bounds } & \multicolumn{2}{|c|}{ Upper bounds } \\
\hline & Average & $\mathrm{SD}$ & Average & $\mathrm{SD}$ & Average & $\mathrm{SD}$ \\
\hline 2 November 2005 & 2701.5352 & 20.6665 & 2635.2601 & 17.6532 & 2767.8118 & 26.7354 \\
\hline 3 November 2005 & 2670.5599 & 21.0942 & 2614.1401 & 21.2338 & 2726.9805 & 21.7381 \\
\hline 4 November 2005 & 2625.2331 & 21.1504 & 2567.1331 & 21.2655 & 2683.3339 & 21.4161 \\
\hline 7 November 2005 & 2593.8850 & 3.2707 & 2536.6710 & 5.1827 & 2651.0995 & 2.6624 \\
\hline 8 November 2005 & 2588.8585 & 19.6584 & 2532.6284 & 20.9490 & 2645.0890 & 1.0054 \\
\hline 9 November 2005 & 2592.8393 & 26.9841 & 2537.1157 & 27.7953 & 2648.5633 & 26.4683 \\
\hline 10 November 2005 & 2542.8534 & 10.2008 & 2485.1180 & 11.3727 & 2600.5893 & 10.3144 \\
\hline 11 November 2005 & 2541.0100 & 5.4132 & 2483.7971 & 6.8919 & 2598.2234 & 3.9797 \\
\hline 14 November 2005 & 2505.2203 & 23.7640 & 2450.4979 & 24.6179 & 2559.9431 & 23.0593 \\
\hline 15 November 2005 & 2468.6977 & 17.8869 & 2414.3327 & 19.2756 & 2523.0631 & 17.0930 \\
\hline 16 November 2005 & 2532.4820 & 35.6121 & 2478.4379 & 36.7870 & 2586.5265 & 34.7736 \\
\hline 17 November 2005 & 2528.8200 & 12.4856 & 2475.5397 & 14.4666 & 2582.1007 & 11.4061 \\
\hline 18 November 2005 & 2455.6649 & 40.4812 & 2397.1779 & 41.3105 & 2514.1523 & 40.8374 \\
\hline
\end{tabular}

Note: Values in euros; second study; strike $=119.5$.

Table 6. Quality option price

\begin{tabular}{|c|c|c|c|c|c|c|}
\hline & \multicolumn{2}{|c|}{ Price (frictionless) } & \multicolumn{2}{|c|}{ Lower bounds } & \multicolumn{2}{|c|}{ Upper bounds } \\
\hline & Average & $\mathrm{SD}$ & Average & $\mathrm{SD}$ & Average & $\mathrm{SD}$ \\
\hline 2 November 2005 & 2703.0460 & 25.7214 & 2647.3592 & 23.0741 & 2758.7339 & 29.1126 \\
\hline 3 November 2005 & 2669.5616 & 19.5506 & 2613.0656 & 19.0674 & 2726.0582 & 20.5792 \\
\hline 4 November 2005 & 2620.1008 & 25.0137 & 2566.1848 & 25.6366 & 2674.0174 & 24.6374 \\
\hline 7 November 2005 & 2593.9671 & 5.2874 & 2536.6570 & 6.7803 & 2651.2778 & 4.1089 \\
\hline 8 November 2005 & 2586.5880 & 21.0829 & 2532.0941 & 20.7937 & 2641.0824 & 21.8136 \\
\hline 9 November 2005 & 2592.3964 & 24.4400 & 2534.7991 & 25.4124 & 2649.9943 & 23.7533 \\
\hline 10 November 2005 & 2543.7435 & 0.0000 & 2487.4522 & 0.0000 & 2600.0351 & 0.0000 \\
\hline 11 November 2005 & 2536.9443 & 3.9127 & 2465.1398 & 2.2731 & 2608.7500 & 6.7599 \\
\hline 14 November 2005 & 2505.2203 & 21.1881 & 2448.0017 & 17.0129 & 2562.4393 & 25.4208 \\
\hline 15 November 2005 & 2469.5885 & 17.3130 & 2398.7092 & 18.9626 & 2540.4690 & 16.0845 \\
\hline 16 November 2005 & 2529.3600 & 36.3622 & 2473.0546 & 36.2082 & 2585.6661 & 37.0461 \\
\hline 17 November 2005 & 2530.6325 & 14.9181 & 2476.5458 & 15.4414 & 2584.7196 & 14.9870 \\
\hline 18 November 2005 & 2473.6097 & 42.5412 & 2416.0036 & 45.0270 & 2531.2161 & 41.1776 \\
\hline
\end{tabular}

Note: Values in euros; second study; strike $=120$. 
Table 7. Quality option price

\begin{tabular}{|c|c|c|c|c|c|c|}
\hline & \multicolumn{2}{|c|}{ Price (frictionless) } & \multicolumn{2}{|c|}{ Lower bounds } & \multicolumn{2}{|c|}{ Upper bounds } \\
\hline & Average & SD & Average & SD & Average & $\mathrm{SD}$ \\
\hline 2 November 2005 & 2704.4210 & 23.8382 & 2648.8597 & 24.6373 & 2759.9832 & 23.3816 \\
\hline 3 November 2005 & 2669.1579 & 22.1661 & 2612.5059 & 21.9277 & 2725.8106 & 23.2784 \\
\hline 4 November 2005 & 2604.5251 & 0.0000 & 2549.0348 & 0.0000 & 2660.0159 & 0.0000 \\
\hline 8 November 2005 & 2598.1949 & 0.0000 & 2497.0581 & 0.0000 & 2699.3328 & 0.0000 \\
\hline 9 November 2005 & 2617.3672 & 13.4810 & 2563.8658 & 15.7231 & 2670.8689 & 12.2962 \\
\hline 10 November 2005 & 2536.0323 & 7.7112 & 2480.2355 & 7.2167 & 2591.8296 & 8.2055 \\
\hline 16 November 2005 & 2557.1168 & 11.0188 & 2501.4849 & 12.5861 & 2612.7494 & 12.3364 \\
\hline 17 November 2005 & 2531.0632 & 14.6291 & 2473.3528 & 15.8074 & 2588.7742 & 15.7793 \\
\hline 18 November 2005 & 2500.5249 & 33.4205 & 2440.1676 & 42.4663 & 2560.8825 & 26.1639 \\
\hline
\end{tabular}

Note: Value in euros; second study; strike $=120.5$.

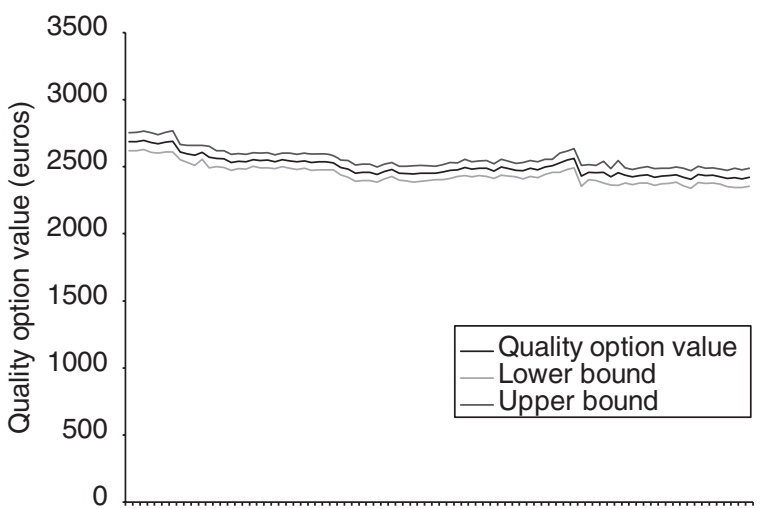

Fig. 4. Quality option price

Note: Value in euros; second study; strike $=119$.

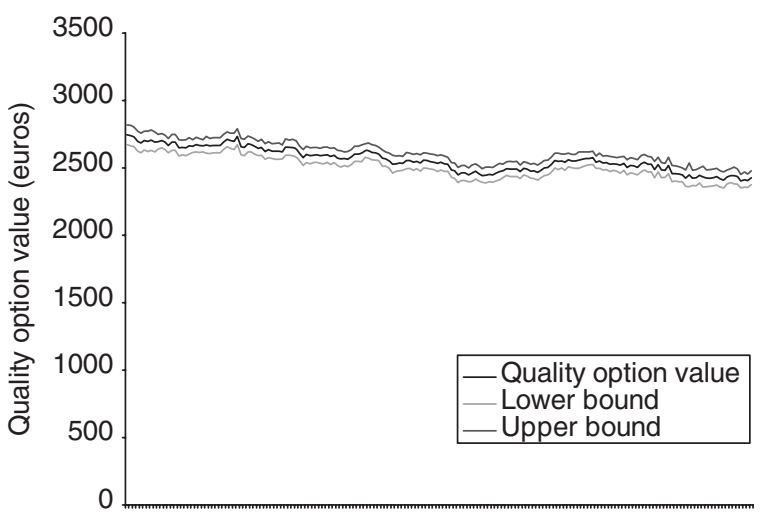

Fig. 5. Quality option price

Note: Value in euros; second study; strike $=119.5$.

despite the presence of several deliverable securities. On the other hand, the presence of the quality option presents an important drawback since hedgers must face basis risk, at least if the quality option price becomes significant. This situation affected the

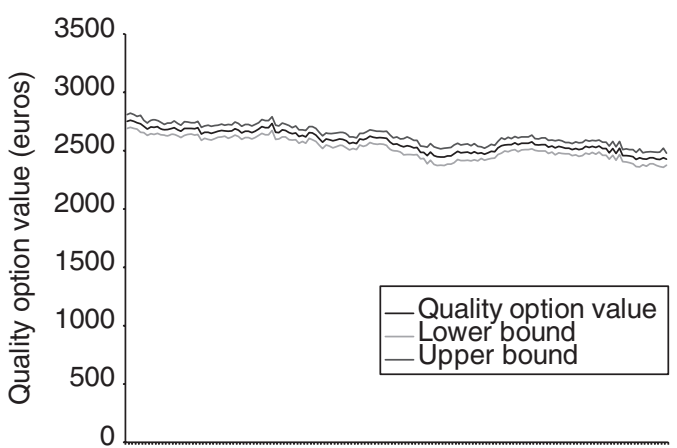

Fig. 6. Quality option price

Note: Value in euros; second study; strike $=120$

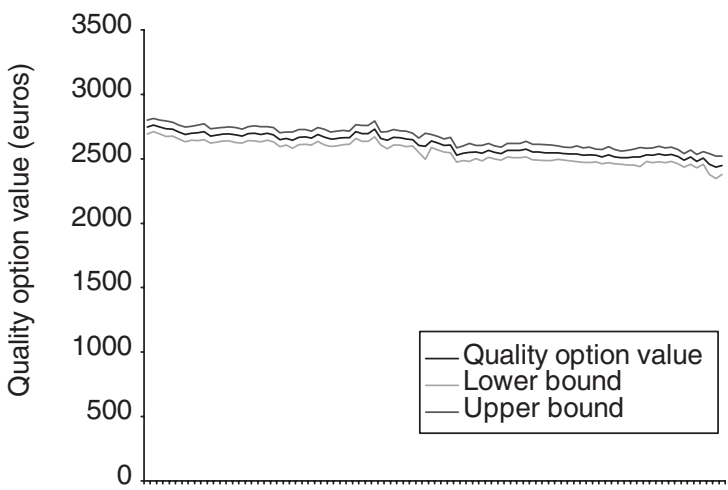

Fig. 7. Quality option price

Note: Value in euros; second study; strike $=120.5$.

contract Government National Mortgage Association Collateralized Depository Receipt (GNMA-CDR). From 1982, the quality option price began increasing and the contract disappeared in 1987, when the trading volume was almost negligible (Johnston and McConnell, 1989). 
Table 8. Profits (euros) and annual returns (percentage) of Strategy $A$ if the quality option is sold at $t_{0}$ and bought at $t_{1}$ (calculated from average bid and ask daily prices)

\begin{tabular}{|c|c|c|c|c|c|}
\hline \multicolumn{3}{|c|}{$t_{1}=26$ November 2002} & \multicolumn{3}{|c|}{$t_{0}=10$ September 2002} \\
\hline$t_{0}$ & $\begin{array}{l}\text { Profit } \\
\text { (euros) }\end{array}$ & $\begin{array}{l}\text { Annual } \\
\text { return (\%) }\end{array}$ & $t_{1}$ & $\begin{array}{l}\text { Profit } \\
\text { (euros) }\end{array}$ & $\begin{array}{l}\text { Annual } \\
\text { return (\%) }\end{array}$ \\
\hline 10 September 2002 & 1326.4874 & 891.2469 & 17 September 2002 & -68.5690 & -170.8391 \\
\hline 17 September 2002 & 1304.9393 & 966.2572 & 24 September 2002 & -9.4567 & -13.9711 \\
\hline 24 September 2002 & 1240.9850 & 1023.1611 & 1 October 2002 & 160.1213 & 145.3539 \\
\hline 1 October 2002 & 1069.8241 & 994.6326 & 8 October 2002 & 392.3715 & 307.1674 \\
\hline 8 October 2002 & 844.8746 & 900.2040 & 15 October 2002 & 623.3121 & 455.3671 \\
\hline 15 October 2002 & 612.8037 & 764.4075 & 22 October 2002 & 786.5686 & 541.9482 \\
\hline 22 October 2002 & 452.2631 & 680.3432 & 29 October 2002 & 910.2638 & 596.8786 \\
\hline 29 October 2002 & 331.3650 & 627.7986 & 5 November 2002 & 1063.6124 & 720.2360 \\
\hline 5 November 2002 & 180.3969 & 438.9743 & 12 November 2002 & 1085.6664 & 666.5216 \\
\hline 12 November 2002 & 160.2349 & 585.7604 & 19 November 2002 & 1182.7969 & 726.9222 \\
\hline 19 November 2002 & 67.2307 & 491.4113 & 26 November 2002 & 1326.4874 & 891.2469 \\
\hline
\end{tabular}

Some authors have analysed the effect of the quality option presence on the effectiveness of the hedging strategies (some recent papers are Rendleman (2004) and Grieves and Marcus (2005)). In general, they report that the quality option reflects a scant influence because the deliverable assets have very correlated prices. Thus, the (cheapest) quality option value will be quite close to zero.

This section is devoted to analysing the (most expensive) quality option as a security that could be interesting to many traders, in the sense that incorporating the quality option in their portfolio could provoke a positive shift of the risk/return efficient frontier. As far as we know, this kind of study has never been addressed in previous literature.

The results of both analysed periods suggest that the quality option price is decreasing, so it could be interesting to sell it (or its replica) so as to buy it again a few days before maturity. This strategy also implies positive effects on the viability of the future contract. Indeed, on the one hand, the sale of the quality option implies the purchase of the future contract (Proposition 1), providing hedgers with liquidity. Similarly, a few days before maturity the sale of the future will again assist hedgers, since they will buy the future if they cannot deal with the cheapest to deliver bond due to manipulations. On the other hand, replicating the most expensive quality option prevents the use of the cheapest to deliver bond, so traders using the quality option as an asset will not be affected by manipulators.

In order to check the effectiveness of the strategy mentioned above in practice, we need some more theoretical results. Let $t_{0}$ and $t_{1}\left(t_{0}<t_{1}<T\right)$ denote two trading dates and consider the sale and purchase of the quality option at $t_{0}$ and $t_{1}$ (henceforth Strategy A).
Remark 12: The cash flow of Strategy A at $t_{1}$ is

$$
\begin{aligned}
& \left(1+r_{0,1}^{b}\right)^{t_{1}}\left(\frac{p_{0, j}^{b}}{\delta_{j}}-\frac{f_{a}}{\left(1+r_{b}\right)^{T}}\right)-\left(\frac{p_{1, j}^{a}}{\delta_{j}}-\frac{f_{1, b}}{\left(1+r_{1, a}\right)^{T-t_{1}}}\right) \\
& j=1,2, \ldots, n
\end{aligned}
$$

where $r_{0,1}$ denotes the riskless rate between $t_{0}$ and $t_{1}$, $r_{a}$ the rates between $t_{0}$ and $T, r_{1, a}$ the rates between $t_{1}$ and $T$, the subscripts 0 or 1 the prices at $t_{0}$ or $t_{1}$, and the subscripts $a$ and $b$ the bid or ask prices, respectively.

If $S_{j}$ pays the dividend $d_{j}$ at $\tau_{0, j}\left(t_{0} \leq \tau_{0, j} \leq T\right)$, then (Equation 10) becomes

$$
\begin{aligned}
(1 & \left.+r_{0,1}^{b}\right)^{t_{1}}\left(\frac{p_{0, j}^{b}}{\delta_{j}}-\frac{f_{a}}{\left(1+r_{b}\right)^{T}}-\frac{d_{j}}{\delta_{j}\left(1+r_{\tau_{0 j}}^{b}\right)^{\tau_{0 j}}}\right) \\
& -\left(\frac{p_{1, j}^{a}}{\delta_{j}}-\frac{f_{1, b}}{\left(1+r_{1, a}\right)^{T-t_{1}}}\right)
\end{aligned}
$$

and if $S_{j}$ pays $d_{j}$ at $\tau_{1, j}\left(t_{1} \leq \tau_{1, j} \leq T\right)$, then (Equation 10) becomes

$$
\begin{aligned}
& \left(1+r_{0,1}^{b}\right)^{t_{1}}\left(\frac{p_{0, j}^{b}}{\delta_{j}}-\frac{f_{a}}{\left(1+r_{b}\right)^{T}}\right) \\
& -\left(\frac{p_{1, j}^{a}}{\delta_{j}}-\frac{f_{1, b}}{\left(1+r_{1, a}\right)^{T-t_{1}}}-\frac{d_{j}}{\delta_{j}\left(1+r_{\tau_{1 j}}^{a}\right)^{\tau_{1 j}-t_{1}}}\right)
\end{aligned}
$$

The expressions mentioned above have been used to compute those profits generated by Strategy A. Annual returns have been computed. Table 8 reflects the results if the sale takes place from 13 to 3 weeks before maturity, and the purchase is implemented 2 weeks before maturity and also it provides the results if one sells 13 weeks before $T$ and buys within 
Table 9. Profits (euros) and annual returns (percentage) of Strategy $A$ if the quality option is sold at $t_{0}$ and bought at $t_{1}$ (calculated from average bid and ask daily prices) $($ strike $=119)$

\begin{tabular}{|c|c|c|c|c|c|}
\hline \multicolumn{3}{|c|}{$t_{1}=18$ November 2005} & \multicolumn{3}{|l|}{$t_{0}=2$ November 2005} \\
\hline$t_{0}$ & Profit (euros) & Annual return $(\%)$ & $t_{1}$ & Profit (euros) & Annual return $(\%)$ \\
\hline 2 November 2005 & 121.2038 & 107.2064 & 4 November 2005 & -50.7584 & -344.8034 \\
\hline 4 November 2005 & 60.9351 & 60.7543 & 7 November 2005 & -45.8506 & -126.0502 \\
\hline 7 November 2005 & 36.8505 & 46.3089 & 8 November 2005 & -44.8930 & -103.2412 \\
\hline 8 November 2005 & 39.6963 & 55.2463 & 9 November 2005 & -15.5066 & -32.3053 \\
\hline 9 November 2005 & 2.2980 & 1.6833 & 10 November 2005 & 16.7697 & 27.0317 \\
\hline 10 November 2005 & -5.0794 & -11.1563 & 11 November 2005 & 19.3459 & 27.7967 \\
\hline 11 November 2005 & -15.4442 & $-33.8213 \%$ & 14 November 2005 & 57.8808 & 65.8449 \\
\hline 14 November 2005 & -48.3522 & -176.3770 & 15 November 2005 & 92.3606 & 99.2861 \\
\hline 15 November 2005 & -84.0373 & -406.1184 & 16 November 2005 & 48.4219 & 46.4599 \\
\hline 16 November 2005 & -49.8165 & -361.3566 & 18 November 2005 & 121.2038 & 107.2064 \\
\hline
\end{tabular}

12 and 2 weeks before $T$. Note that transaction costs have been discounted. Table 9 reports the results of the second study. ${ }^{7}$

The highest value of the two tables equals $1023.1611 \%$. This is an annual return generated if one sells the quality option replica on 24 September 2002 and buys it on 26 November 2002. We have calculated annual returns with the formula

$$
\mathrm{AR}=\frac{V-C}{C} \frac{360}{t_{1}-t_{0}} 100
$$

where $V$ being the quantity received for the sale of the quality option, $C$ the price paid to buy it later and $t_{1}-t_{0}$ denoting the number of days between both transactions.

The average quantity received for the sale of the quality option on 24 September 2002 is 1934.7991 euros (lower bound for the quality option price) and the average paid price paid on 26 November 2002 is 700.4784 euros (upper bound for the quality option price). The number of days between both transactions is 62. Therefore, the annual return equals $1023.1611 \% .^{8}$ Note that agents can really benefit from Strategy A. Profits are higher if one sells 13 weeks before maturity and keeps the option for more than 8 weeks.

\section{Conclusions}

The quality option embedded in many future contracts may be replicated by using a static approach.
It allows us to provide several replicating portfolios since future calls and puts may be incorporated. Furthermore, the static analysis makes it far easier to take transaction costs into account when pricing the quality option.

The results of each empirical analysis based on the static approach seem to be very robust. Indeed, they do not depend on any dynamic hypothesis, they have to overcome several tests due to the existence of different replicating portfolios, they can be obtained from perfectly synchronized real market high frequency data and they can incorporate imperfections and the information contained in a large set of assets. These properties are important since previous literature shows great variation in different authors' estimates of the quality option value. Therefore, a high degree of precision in the analysis must be respected in order to achieve correct values.

Although the methodology applies for future contracts on quite different sorts of securities, we have empirically tested a bond market, since this is the most usual case in practice. We have checked the quality option of the German Bund Future Contract. Three months before maturity, the (most expensive) embedded quality option approximate average value lies within the spread $[1.9 \%, 2.8 \%]$, which is far from being a negligible price. This may justify that, as pointed out by other authors, the presence of quality options has to be considered when pricing future derivatives and testing the market efficiency. To ignore this presence may provoke speculative strategies trying to benefit from possible market inefficiencies.

\footnotetext{
${ }^{7}$ Profits and annual returns have been calculated for the strike 119 .

${ }^{8}$ Once again, it is worthwhile to recall that we do not trade the quality option, but its replica. Thus, these prices and annual returns have been computed by using available securities and their real perfectly synchronized quotes, as provided by Bloomberg. They would remain the same if the pricing model of the quality option were modified. Furthermore, the bid/ask spread has been considered
} 
Finally, it has been shown that the quality option could be a useful asset by itself, in the sense that many traders could incorporate it (in short position) in order to improve the risk/return efficient line. Traders implementing this strategy will preserve the future contract hedging effectiveness, make the hedging demand of the future contract increase and compensate the effect of possible manipulations.

\section{Acknowledgements}

This research was partially supported by the Comunidad Autónoma de Madrid (Spain), grant no. S 2009/ESP-1494, and MEyC (Spain), grant no. ECO2009-14457-C04.

\section{References}

Ahn, H., Cai, J. and Cheung, J. (2002) What moves German Bund futures contracts on the Eurex?, The Journal of Futures Markets, 22, 679-96.

Balbás, A., Longarela, I. R. and Pardo, A. (2000) Integration and arbitrage in the Spanish financial market: an empirical approach, The Journal of Futures Markets, 20, 321-44.

Barnhill, T. (1990) Quality option profits, switching option profits, and variation margin costs: an evaluation of their size and impact on treasury bond futures prices, Journal of Financial and Quantitative Analysis, 25, 65-86.

Barnhill, T. and Seale, W. (1988) Optimal exercise of the switching option in treasury bond arbitrages, The Journal of Futures Markets, 8, 517-32.

Bick, A. (1997) Two closed-form formulas for the futures price in the presence of a quality option, European Finance Review, 1, 81-104.

Boyle, P. (1989) The quality option and timing option in futures contracts, The Journal of Finance, 44, 101-13.

Chance, D. M. and Hemler, M. L. (1993) The impact of delivery options on futures prices: a survey, The Journal of Futures Markets, 13, 127-55.

Chen, R. R. (1997) Bounds for treasury bond futures prices and embedded delivery options, Working Paper, Rutgers University, New Brunswick.

Chen, R. R., Chou, J. H. and Lin, B. H. (1999) Pricing the quality option in Japanese government bond futures, Applied Financial Economics, 9, 51-65.

Cherubini, U. and Exposito, M. (1995) Options in and on interest rate futures contracts: results from Matingale pricing theory, Applied Mathematical Finance, 2, 1-5.

Cox, J., Ingersoll, J. and Ross, S. (1985) A theory of the term structures of interest rates, Journal of Financial Economics, 9, 321-46.

Gay, G. and Manaster, S. (1991) Equilibrium treasury bond futures prices in the presence of implicit delivery options, The Journal of Futures Markets, 11, 623-45.

Grieves, R. and Marcus, A. (2005) Delivery option and treasury-bond futures hedge ratios, Journal of Derivatives, 13, 70-6.

Heath, D., Jarrow, R. and Morton, A. (1992) Bond pricing and the term structure of interest rates: a new methodology for contingent claims valuation, Econometrica, 1, 77-105.

Hedge, S. (1990) An ex post valuation of the quality option implicit in the treasury bond futures contract, Journal of Banking and Finance, 14, 741-60.

Hemler, M. (1990) The quality delivery option in treasury bond futures contract, The Journal of Finance, 45, 1565-86.

Henrard, M. (2006) Bonds futures and their options: more than the cheapest to deliver; quality option and margining, Journal of Fixed Income, 16, 62-76.

Hull, J. and White, A. (1990) Pricing interest rate derivative securities, The Review of Financial Studies, 3, 573-92.

Järvinen, S. and Käppi, J. (2004) Manipulation of the bund futures market, Applied Financial Economics, 14, 799-808.

Johnston, E. and McConnell, J. (1989) Requiem for a market: an analysis of the rise and fall of a financial future contract, The Review of Financial Studies, 2, $1-23$.

Jouini, E. and Kallal, H. (1995) Martingales and arbitrage in securities markets with transaction costs, Journal of Economic Theory, 66, 178-97.

Kamara, A. (1990) Delivery uncertainty and the efficiency of futures markets, Journal of Financial and Quantitative Analysis, 25, 45-64.

Kane, A. and Marcus, A. (1986) The quality option in the treasury bond futures market: an empirical assessment, The Journal of Futures Markets, 6, 231-48.

Lieu, D. (1990) Option pricing with futures-style margining, The Journal of Futures Markets, 10, 327-38.

Lin, B. H. and Paxson, D. A. (1993) Valuing the 'new-issue' quality option in bund futures, The Review of Futures Markets, 12, 347-88.

Margrabe, W. (1978) The value of an option to exchange one asset for another, The Journal of Finance, 33, 177-86.

Merrick, J. J., Naik, N. Y. and Yaday, P. K. (2005) Strategic trading behavior and price distortion in a manipulated market: anatomy of a squeeze, Journal of Financial Economics, 77, 171-218.

Rendleman, R. (2004) Delivery option in the pricing and hedging of treasury bond and note futures, Journal of Fixed Income, 14, 20-31.

Ritchken, P. and Sankarasubramanian, L. (1995) A multifactor model of the quality option in treasury futures contracts, The Journal of Financial Research, 3, 261-79.

Ronn, E. and Bliss, R. (1994) A nonstationary trinomial model for the valuation of options on treasury bond futures contracts, The Journal of Futures Markets, 14, 597-617.

Stickland, C. (1992) The delivery option in bond futures contracts: an empirical analysis of the LIFFE long gilt future contract, The Review of Futures Markets, 11, 84-102.

Vasicek, O. A. (1977) An equilibrium characterization of the term structure, Journal of Financial Economics, 5, $177-88$.

Vidal, J. and Ferreira, L. (2007) Multifactor and analytical valuation of treasury bond futures with an embedded quality option, Journal of Futures Markets, 27, 275-303.

Yu, S. W. (1997) Term structure of interest rates and implicit options: the case of Japanese bond futures, Journal of Business Finance and Accounting, 24, 593-614. 